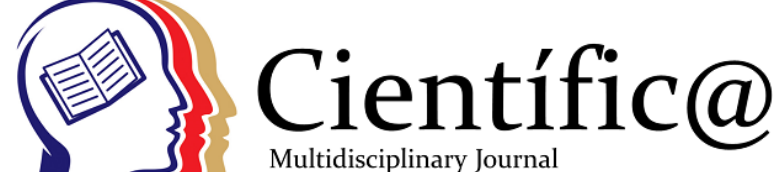 e-ISSN 2358-26oX
}

\section{OTIMIZAÇÃO DO BENEFICIAMENTO DO CACAU (Theobroma cacao L)}

\section{THE OPTIMIZATION OF BENEFICIATION OF CACAO (Theobroma cacao L)}

\author{
Adriane Ferreira de Miranda ${ }^{1 *}$, Maricely Uria Toro ${ }^{2}$
}

\author{
${ }^{1}$ Universidade Tecnológica Federal do Paraná (UTFPR), Pós Graduanda em Tecnologia de Alimentos (PPGTA); * \\ adrianeferreiram@gmail.com \\ ${ }^{2}$ Universidade do Estado do Pará (UEPA), Centro de Ciências Naturais e Tecnologia (CCNT), Docente no (DETA) em Belém, \\ Pará, Brasil.
}

\section{Info}

Recebido: 09/2020

Publicado: $12 / 2020$

DOI: $10.29247 / 2358-260 X .2020 v 7 i 2.4753$

ISSN: 2358-260X

\section{Palavras-Chave}

Cacau. Biodiversidade. Fermentação.

Keywords:

Cocoa. Biodiversity. Fermentation.

\begin{abstract}
This work aimed to optimize the beneficiation of cacao beans (Theobroma cacao l) using a sustainable fermenter. This was done by formulating an alternative broth containing the co-product of the initial fermentation (f1), to improve the extract for cultivation of the specific microorganisms, followed by the activation and replication of the yeast strains, in order to achieve the multiplication in biomass of the start cells to reach a proportion where they can be re inoculated into the fermentation stage intended to be optimized (f2). The cacao samples must undergo safe and efficient processes since biochemical transformations that cause sensory changes take place during these steps. The following parameters were observed during Initial (F0) and final (F1) Fermentation, Drying, Roasting at $170^{\circ}$
\end{abstract} C: Temperature ${ }^{\circ} \mathrm{C}, \mathrm{pH},{ }^{\circ} \mathrm{Brix}$, Moisture (\%), Ash (\%), Protein (\%), Lipids (\%), Microbiology (CFU) in trials with start inoculum (f2) and those without inoculum (f1). The results of the analyses indicate a reduction of fermentation time from 7 to 5 days, as represented by an increase in the $\mathrm{pH}$ of 5.19 and decline of $\mathrm{o}$ Brix on day 5, as well as greater availability of phenolic compounds 331.5 mg.AG. g-1 and Antioxidant Activity 148.5 $\mu \mathrm{mol}$. Trolox.g. This allows us to conclude that the optimization performed resulted in nibs with better biochemical availability than those obtained through the conventional trial

\section{Resumo}

O trabalho versa na otimização do beneficiamento dos nibs do cacau (Theobroma cacao L) utilizando fermentador sustentável; formulando o caldo alternativo que contém o co-produto da fermentação inicial (f1) para auxiliar no extrato para o cultivo dos microrganismos específicos, seguido da ativação e repique das cepas leveduriformes para o alcance da multiplicação na biomassa de células start até uma proporção que possam ser reinoculadas na etapa da fermentação a ser otimizado (f2), onde as amostragens são cacau (cultura pura) coletado durante o beneficiamento, para isso, as amêndoas de cacau necessitam serem submetidos a processos seguros e eficientes, já que nestas etapas ocorrem transformações bioquímicas que desencadeiam os precursores sensoriais do chocolate. Foi observado mediante o monitoramento das amostras a partir do programa de estatística $\mathrm{R}$ durante as etapas da Fermentação inicial (F0) e final (F1); Secagem; Torração a $170{ }^{\circ} \mathrm{C}$; Temperatura ${ }^{\circ} \mathrm{C}$, $\mathrm{pH}$, Sólidos solúveis totais (o Brix), Umidade (\%), Cinzas (\%), Proteínas (\%), Lipídios (\%), Microbiologia (UFC) nos ensaios sem (f1) e com inóculo start (f2). Os resultados referente às análises encontrados direcionam a uma redução do tempo de fermentação de 7 para 5 dias, sustentado com aumento no pH 5,19 e declínio do oBrix no $5^{\circ}$ dia, maior disponibilidade para Compostos Fenólicos 331,5 mg.AG. g-1 e Atividade Antioxidante 148,5 $\mu$ mol.Trolox.g o que permite concluir que a otimização efetuada foi potencialmente preferível e obteve nibs com disponibilidade bioquímica mais eficientes que os nibs resultantes do ensaio para o beneficiamento convencional efetuado por produtores tradicionais 


\section{INTRODUÇÃO}

"A produção de cacau do Pará é de 132 mil t/ano e atualmente é o maior produtor do Brasil" (Governo do Estado do Pará, 2019). O consumo do cacau oscila de acordo com os de costumes de cada região de origem, sendo consumido in natura ou na forma de produtos como chocolate, achocolatado, chocolate em pó, licor fino, bebida fermentada e calda a base do chocolate. Estes derivados do cacau também são muito consumidos em produtos de confeitaria por serem utilizados como matérias primas na elaboração de bolos, sorvetes, mousses e etc (OLIVEIRA 2015).

"O termo Theo (Deus) broma (alimento) advém da lenda asteca que se refere ao fruto do cacau como um alimento dos deuses" (OETTERER et al., 2006). "Pertencente à família Sterculiacea, árvore de cultura perene, nativa das matas equatoriais da região Amazônica, América do Sul e Central", de solos profundos, permeáveis, férteis ou adubados, necessitando de sombra. O plantio deve ser feito na época das chuvas cuja floração acontece no verão e sua frutificação entre outono e inverno e sua propagação se dá mediante as sementes que constituem a parte econômica do cultivo, variam em forma e tamanho, segundo a variedade; são, via regra, achatadas. (CRUZ 2012; SANTOS 2010; DEUS 2015; PEREIRA 2013), fornecendo a matéria prima para a elaboração do chocolate, produto altamente energético e mundialmente consumido (LEITE 2012; CAVALCANTE 2010; MAKI 2006) o que faz deste fruto um alimento de exacerbada excelência, ao que se refere às inúmeras riquezas naturais da Amazônia Paraense. Firma-se como um alimento apreciado por sua singularidade de aspecto sensorial e nutricional benéfica ao metabolismo humano, sendo sua composição de pericarpo (casca) e polpa carnosa, figura 1, com variação na forma, tamanho e cor. Nas amêndoas da semente existe também fécula, açúcar, amido, ácido oxálico, tanino e enzimas hidrolisantes. A semente contém 34-56 \% de matéria graxa e óleo e a polpa adocicada contém $12 \%$ de sacarina e quando fermentada produz o exsudado do cacau, licor, vinagre fino, álcool de boa qualidade.

As etapas de fermentação e secagem estão inclusas nas sequências das operações específicas associadas ao processo racional de beneficiamento das sementes de cacau e que em conjunto, corroboram para a elevação da qualidade final das amêndoas, uma vez que sejam de vital importância, pois atuam como a principal matéria prima na elaboração de uma variedade de produtos derivados do cacau, e que nenhum outro processamento posterior (conservação e transporte) é capaz de corrigir falhas nestas etapas iniciais de beneficiamento (BRITO 2013).

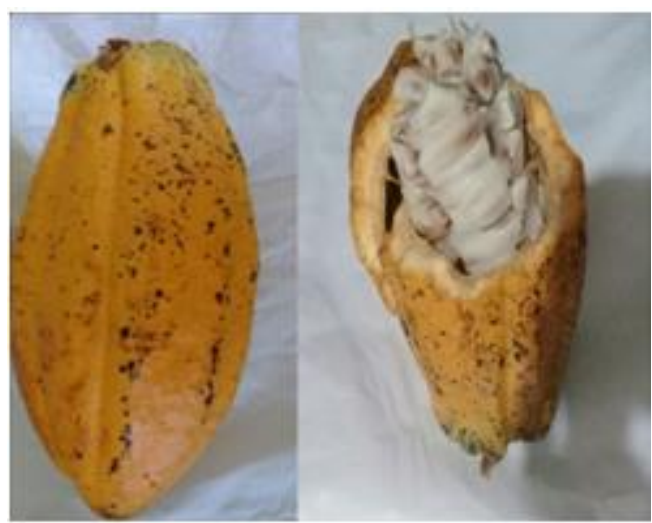

FIGURA 1 - Ilustração do Fruto do cacau. Fonte - Autor, 2020.

\subsection{Fermentações do cacau}

A Fermentação é um processo metabólico exotérmico onde há produção de energia na forma de calor, devido às complexas reações que culmina na morte do embrião, com isso os compostos fenólicos entram em contato com as enzimas polifenoloxidase e glicosidase presentes das sementes, ocasionando reação de oxidação, complexação com proteínas e formação de pigmentos, como as quinonas (DIAZ 2016). O processo fermentativo é antigo e tradicionalmente aplicado para produzir, conservar e/ou modificar o 
flavor desagradável, adstringente e amargo das amêndoas, característico da transformação tecnológica do cacau em chocolate e dos diversos produtos análogos do cacau (AMORIM 2005; PRADO 2007; SANTOS 2010; SERRA et al., 2016).

A matéria orgânica exposta ao processo é um sistema de moléculas complexas, mas são sintetizados a outras moléculas mais simples, devido à ação incessante de certos microrganismos denominados fermentos, estando intrínseca ao alimento in natura, por esse motivo a fermentação torna-se responsável pelo início da formação dos precursores sensoriais do chocolate (NELSON e COX 2014; ALMEIDA et al., 2011).

Entre os parâmetros que compõem e contribuem para o processo fermentativo está à temperatura, a acidez em que se encontram as sementes, o intervalo de tempo que desencadeia todo o processo e principalmente a capacidade de degradação das leveduras, juntamente com a microflora que constitui o ambiente em que o fruto é submetido ao iniciar o processo (CRUZ 2012).

$\mathrm{O}$ ambiente que favorece a fermentação está relacionado à manutenção das boas práticas do manipulador e equipamentos, consecutivamente, podendo haver contaminação cruzada, pois neste, há presença de substratos formados pela contaminação com microrganismos endofíticos (MAKI 2006), contaminantes naturais da planta e fungos não causadores de danos ao hospedeiro (Colletotrichum spp), certas espécies crescem e se proliferam, outras são mortas por conta da disputa por nutrientes, condições ambientais do sistema o qual estão dispostas, tipo de fermentação, pH, temperatura, carboidratos, aeração, etc (MIGLIARI 2001).

\subsection{Reações de Maillard}

A despigmentação das amêndoas do cacau é provocada pela reação e interação do grupo amina com açúcar redutor (aldeído), um monossacarídeo, via condensação do grupo carbonila com a amina (ataque nucleofílico do par de elétrons do nitrogênio do grupo amina); seguem com a eliminação de água e formação da glicosilamina, estas reações acontecem a partir de condições apropriadas e a velocidade depende de fatores, como temperatura $>40^{\circ} \mathrm{C}$, atividade de água, pH na faixa de 6,0 a 8,0 umidade relativa 30 a $70 \%$, açúcar redutor, quantidade de oxigênio, presença de metais, fosfatos e dióxido de enxofre (RIPPER 2015; NESPOLO et al., 2015; SILVA et al., 2014).

\subsection{Fases de ação das leveduras}

Leveduras possuem mecanismo genético para metabolizar açúcares por dois processos distintos para o alcance de energia, aeróbica (respiração) ou anaeróbica (fermentação). Uma vez que crescem e se reproduzem mais rapidamente que bolores, são aeróbios facultativos, logo, adaptam-se metabolicamente a presença ou ausência de $\mathrm{O}_{2}$ (BARROS 2013; LIMA 2001).

Os principais microrganismos que atuam no processo de fermentação de certos alimentos são leveduras, onde, degradam e consomem os substratos como açúcares simples, da polpa do cacau, expelindo enzimas para produzir biomassa e metabólitos a partir dessa degradação, modificando o composto inicial, sendo os propulsores dos pigmentos intrínsecos as amêndoas de cacau, produzem etanol, ácidos e subprodutos modificados, objetivando características desejáveis ao produto final (ALMEIDA et al., 2011; LIMA 2001).

A ótima predominância das células leveduriformes, está nas temperaturas mesófilas, entre $25-28{ }^{\circ} \mathrm{C}$, em alimentos líquidos, que por serem unicelulares se dispersam melhor nesse ambiente, proliferam-se em distintas concentrações de $\left(\mathrm{CO}_{2}\right)$ e adaptam-se em ambientes com $\mathrm{pH}$ ácido com ótima 
atividade na faixa de 4,0 a 4,5 (SILVA et al.,2017), excretando enzimas responsáveis por degradar a polpa e serem convertidas em produtos finais de interesse (AMORIM 2005).

\subsection{Secagem}

O processo é essencial, pois mantém a estabilidade e qualidade das amêndoas requerida pelo comércio de distribuição. Este tratamento requer a umidade necessária para o armazenamento, também proporciona a continuidade das reações químicas concomitantes que estabilizam a cor marrom, característica das amêndoas do cacau processadas, além de ser a etapa responsável pela redução da acidez final (IMBERTI 2017; CRUZ 2012).

A proposta deste trabalho concerne além da inserção de um fermentador sustentável; a elaboração de um coquetel start obtido no processo da fermentação convencional inicial $\left(f_{1}\right)$, objetivando o melhoramento e a padronização do processo fermentativo para por fim, obter a matéria prima final de qualidade, exacerbada além de apresentar uma alternativa acessível para o beneficiamento do cacau, corroborando para agregação de valor da cadeia produtiva do cacau.

\section{MATERIAIS E MÉTODOS}

\subsection{Coletas amostrais no processo de fermentação $\left(f_{1}\right)$}

As amostras foram retiradas em diferentes pontos do fermentador, aleatoriamente, onde as sementes foram introduzidas em sacos de polietilenos estéreis, e as amostras líquidas (exsudado) foram retiradas do fermentador com o auxílio de uma pipeta Pasteur e acondicionadas em garrafas plásticas estéreis que suportam até $10 \mathrm{~g}$, os recipientes contendo as amostras foram codificadas de acordo com o dia e temperatura na qual se encontravam em cada uma das etapas que compõe o beneficiamento do cacau para elaboração dos nibs finais e em seguida, foram armazenadas em uma caixa térmica de isopor a temperatura inferior a $-5{ }^{\circ} \mathrm{C}$. Parte das amostras foi direcionada para a realização das análises físicas, físicoquímicas e bioquímicas no laboratório de Tecnologia de Alimentos e Química da UEPA, Campus V/CCNT e outra parte utilizada para isolar as células leveduriformes por semeadura, e plaqueamento do analíto, após a diluição em série, as análises microbiológicas foram executadas no LAMICRO, laboratório de microbiologia, do Laboratório Central do Pará, LACEN-PA. Dos reagentes utilizados estão SCMA, para atividade antioxidante; Microscópio óptico-XSZ21-05b.

\subsubsection{ENSAIO DA FERMENTAÇÃO EM FERMENTADOR SUSTENTÁVEL - $\left(f_{1}\right)$}

O fermentador é composto de material isolante, folha de compensado, confeccionado no laboratório de Designer/CCNT, contém um compartimento central, removível, com orifícios, preparado mediante a técnica do filetador em garrafas PETs para captar o exsudado do cacau resultante do processo fermentativo das amêndoas para que possa ser reaproveitado na formulação do caldo alternativo para multiplicação de microrganismos de interesse. Nesse processo da fermentação continha $1,835 \mathrm{~kg}$ de sementes e foi monitorado durante sete dias, realizando revolvimentos nos intervalos, seqüenciais: -0 h, 24 h, 48 h, 72 h, 96 h, 120 h, 144 h e 168 horas em que ocorreu esta etapa.

\subsubsection{Avaliação da Qualidade das Amêndoas}

Aplicada ao final da etapa de secagem com a finalidade de avaliar o grau e a qualidade das amêndoas submetidas às etapas de fermentação. Foram coletadas 100 amêndoas aleatoriamente e então submetidas a cortes longitudinais, com o auxílio de um material de superfície cortante, devidamente higienizado, 
classificando-as se estas estavam aptas ou não a serem comercializadas, considerando a coloração e a compartimentação dos cotilédones (BRASIL 2008).

\subsection{METODOLOGIAS PARA OBTENÇÃO}

\section{CULTURA START}

O método corresponde à inoculação de uma cultura pura de cepas isoladas da fermentação inicial $\left(f_{1}\right)$ no meio fermentativo a ser otimizado $\left(f_{2}\right)$. O procedimento para a aquisição da cultura start iniciou após a certificação do crescimento dos fungos em placas contendo ágar DRBC, o ensaio procedeu com o repique do material após a seleção e isolamento destes para que então possa dar inicio a multiplicação dos microrganismos de interesse (células leveduriformes) em ágar SABOURAUD e caldo nutritivo, respectivamente, para que por fim, mediante o microcultivo das cepas, estas possam ser reativadas até certa proporção que possa garantir o desenvolvimento positivo e preliminar do coquetel start. As análises bioquímicas efetuadas nos nibs resultantes da fermentação inicial e com inóculo start foi parâmetro para avaliar a tendência do procedimento proposto para com a otimização da fermentação das amêndoas proposta neste estudo.

\subsubsection{Crescimento, separação e isolamento de} Células Leveduriformes

\subsubsection{Pré-tratamento das amostras}

$\mathrm{Na}$ primeira diluição seriada analítica $10^{-1}$, figura 2, contém $25 \mathrm{~g}$ das amostras amêndoas e exsudado em $225 \mathrm{~mL}$ de APT (diluente esterilizante). As diluições decimais sucessivas iniciam após a transferência de $1 \mathrm{~mL}$ da diluição inicial, com auxílio de pipeta estéril para o tubo de ensaio contendo $9 \mathrm{~mL}$ de água peptonada (AP) 10-2 e finaliza após a diluição 10-3 obtida de maneira similar a diluição anterior (SILVA et al., 2017).
DA

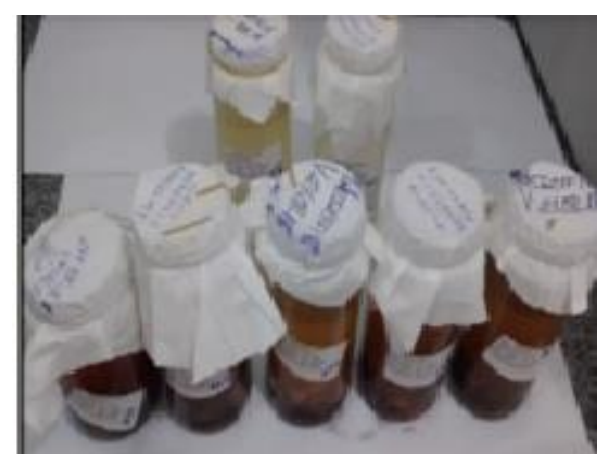

FIGURA 2 - Amostragens em água peptonada tamponada (APT) estéreis, diluições $10^{-1}$.

\subsubsection{Plaqueamento para o crescimento das células leveduriformes}

O método baseia se na semeadura de alíquotas amostrais retiradas de cada uma das diluições decimais seriadas citadas acima na superfície de placas, para isso, foi semeado alíquotas de $0,1 \mathrm{~mL}$ com auxílio da pipetas esterilizadas no centro da superfície de placas descartáveis (Spread Plate), utilizando o bastão de vidro em L, para espalhar uniformemente o inóculo na superfície do meio sólido ágar Dicloran Rosa de Bengala Cloranfenicol (DRBC), que contém antibiótico inibidor de bactérias. As placas foram invertidas e incubadas durante 3 a 5 dias a $25 \pm 1{ }^{\circ} \mathrm{C}$ em Demanda Bioquímica de Oxigênio (DBO) (SILVA et al., 2017; VIEIRA et al., 2006).

\subsubsection{Caracterização morfológica - microscópica e coloração de Gram}

Após a semeadura das amostras nas placas para prosseguir com a incubação e crescimento de colônias fúngicas, realizou-se a leitura quanto às conformações morfológicas macroscópicas, o diâmetro das colônias, aspecto sensorial: forma, tamanho, pigmento para então prosseguir com o esfregaço daquelas que possuem características típicas para leveduras, forma ovóide, pigmento diferenciado e rugosidade, mediante a técnica referente à preparação a fresco que inicia com o esfregaço do material, com auxílio de uma alça de 
platina flambada e resfriada e transferir para uma lâmina de borda fosca, codificada, seguido de uma gota de lactofenol ou azul de metileno e sobrepõe a lamínula para confirmar a identificação das células leveduriformes mediante leitura em microscópio óptico, figura 3 (OLIVEIRA 2015; SOUZA et al., 2012; GUTIÉRREZ 2007; MIGLIARI 2001).

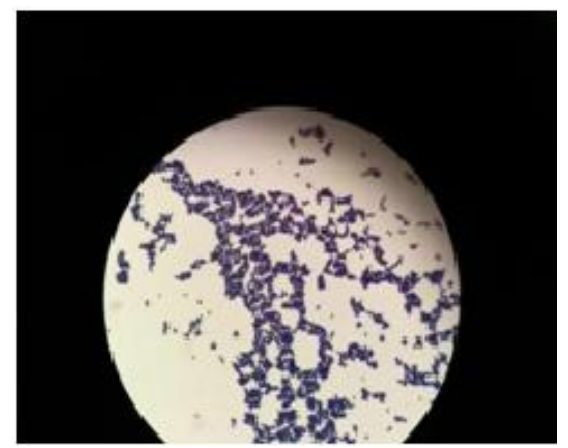

FIGURA 3 - Análise microscópica das células leveduriformes.

\subsubsection{Técnica de Microcultivo}

Após confirmação do material de interesse (células leveduriformes), o repique destas foi efetuado individualmente com auxílio da alça de platina para tubos de ensaios grandes inclinados contendo ágar SABOURAUD Dextrose (SDA) sólido, para serem ativadas como culturas puras. Os 12 tubos contendo cepas isoladas da fermentação inicial $\left(f_{1}\right)$ foram envolvidos por PARAFILM 'M' para isentar o contato com o meio externo e então incubar os tubos de ensaio em DBO a $25{ }^{\circ} \mathrm{C}$ durante \pm 30 dias, conforme
(Sbravatti Junior et al., 2013).

\subsubsection{Caldo alternativo para Leveduras}

O caldo é responsável por multiplicar a biomassa das células a certo volume que assegure a otimização da fermentação $\left(f_{2}\right)$, e para agregar valor aos produtos derivados do cacau, neste caldo $(\mathrm{g} / \mathrm{mL})$ de água destilada, para cada formulação proposta os componentes estão descritos na tabela 1 , as três formulações contém exsudado do cacau, que foi captado no segundo dia (48 h) da fermentação inicial. Os caldos foram autoclavados a $121^{\circ} \mathrm{C} / 15 \mathrm{~min}$ e o $\mathrm{pH}$ ajustado para 5,0, com auxílio de uma solução ácida de $\mathrm{HCl}$ 0,1 N, pois leveduras crescem em pH amplo sendo o pH 5,0 o adequado para o melhor desenvolvimento destas, segundo (SILVA et al., 2017).

Cada cepa isolada dos estágios monitorados durante a fermentação inicial $\left(f_{1}\right)$ foram inoculadas para as 3 três formulações de caldo, contendo $9 \mathrm{~mL}$ em cada um dos tubos, totalizando 30 tubos submetidos a incubação em DBO a $25^{\circ} \mathrm{C}$ por $\pm 72 \mathrm{~h}$.

Os tubos positivos da etapa anterior foram para centrífuga, marca (QUIMIS - 222-T) durante 40 min a 2270 RPM, onde as partículas de maior densidade, por inércia, são arremessadas para o fundo. Neste período de decantação das células, o sobrenadante é descartado e a proporção retida nos tubos foi direcionada para compor o coquetel final de $2,02 \mathrm{~g}$.

Tabela 1 - Formulações dos caldos de enriquecimento para Leveduras.

\begin{tabular}{|c|c|c|}
\hline Abreviação & Formulação & Componentes $(\%)$ \\
\hline F.M & Maltose & $\begin{array}{l}3 \text { de exsudado do cacau, } 5 \text { de } \\
\text { peptona e } 15 \text { de maltose } \\
\text { monohidratada. }\end{array}$ \\
\hline F.G & Glicose & $\begin{array}{l}3 \text { de exsudado do cacau, } 5 \text { de } \\
\text { peptona e } 2 \text { de D-glicose anidra } \\
\text { dextrose. }\end{array}$ \\
\hline F.MG & Maltose e Glicose & $\begin{array}{l}3 \text { de exsudado do cacau, } 5 \text { de } \\
\text { peptona, } 2 \text { de D-glicose anidra } \\
\text { dextrose e } 15 \text { de maltose } \\
\text { monohidratada. }\end{array}$ \\
\hline
\end{tabular}


(SILVA et al., 2017).

\subsubsection{Fermentação com indução do coquetel}

start $-\left(f_{2}\right)$

O coquetel start, figura 4, foi introduzido na fermentação $\left(f_{2}\right)$ na proporção $0,13 \%$ por $\mathrm{kg}$ de amêndoas, o coquetel foi ressuspenso em $5 \mathrm{~mL}$ de água destilada e homogeneizado por 15 min em agitador magnético em seguida despejado em 1,555 kg de massa de cacau.

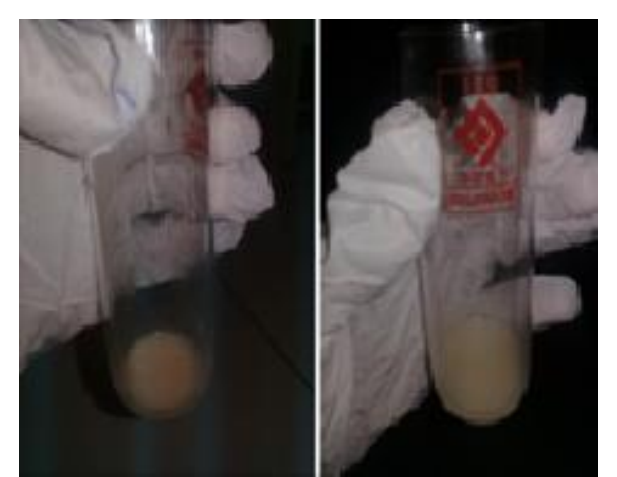

FIGURA 4 - Coquetel start final.

\subsubsection{Secagem Artificial}

Após os 7 dias de duração da fermentação, as sementes foram submetidas à secagem a temperatura de $60^{\circ} \mathrm{C}$ durante 20 horas em estufa com circulação de ar forçada para retirada de umidade que finaliza quando alcançar peso constante do recipiente contendo as amêndoas secas.

\subsubsection{Torração}

O processo de torra ocorreu em forno de panificação a $170^{\circ} \mathrm{C} / 40 \mathrm{~min}$, este procedimento é responsável por intensificar o pigmento e flavor inconfundível do chocolate, concomitante a reação de Maillard, a inativação de enzimas lipolíticas além da diminuição da umidade e redução de ácidos voláteis das amêndoas. Ao final desta etapa, foi removida a película que circunda o cotilédone, o processamento foi finalizado com a cominuição destes em Sire Cutter, dando origem ao nibs torrado das amêndoas de cacau

\subsection{AVALIAÇÕES DOS PARÂMETROS FERMENTATIVOS E ANÁLISE BIOQUÍMICA NOS NIBS DE CACAU}

\subsubsection{Avaliação da temperatura no beneficiamento}

O monitoramento ocorreu aferindo com auxílio do termômetro na massa de cacau durante a fermentação, também na etapa de secagem e torração do produto acabado, nibs.

\subsubsection{Determinação do $\mathrm{pH}$}

Foi realizado segundo método do (Instituto Adolfo Lutz 2008). A concentração desses íons $\mathrm{H}^{+}$é mensurada e expressa através da leitura direta em $\mathrm{pH}$ metro digital (QUIMIX).

\subsubsection{Determinação dos Sólidos Solúveis Totais ( $\left.{ }^{\circ} \mathrm{Brix}\right)$}

Realizada em refratômetro de bancada Abbe, conforme normas da AOAC (2005).

\subsubsection{Determinação de Umidade}

Determinado com a secagem direta em estufa, em triplicata, método por gravimetria, utilizando estufa com circulação de ar a temperatura de $60{ }^{\circ} \mathrm{C}$ até peso constante de acordo com os métodos descritos pela AOAC (2005) n $n^{\circ}$ 925. Os resultados são expressos em porcentagem de umidade.

\section{Cálculo}

Matéria seca $(\%)=(P c+$ amostra $-P c) \times 10 \div P$ $P_{\text {ctamostra }}=$ Peso do cadinho tratado mais amostra

$\mathrm{P}_{\mathrm{C}}=$ Peso do cadinho tratado

$\mathrm{P}=$ Peso inicial da amostra $(\mathrm{g})$

\subsubsection{Lipídios Totais}

O teor de lipídios contido nas amostras de 
cacau foi determinado pelo método de Soxhlet conforme descrito por (Instituto Adolfo Lutz, 2008).

Cálculo

Lipídios $(\%)=(R 0-R f) x 100 \div P$

$\mathrm{R}_{0}=$ Reboiler inicial

$\mathrm{R}_{\mathrm{f}}=$ Reboiler final

$\mathrm{P}=$ peso da amostra inicial $(\mathrm{g})$

\subsubsection{Cinzas Totais}

Consiste em pesar 2,0 $\mathrm{g}$ de amostra no cadinho, previamente tratado em estufa a $105^{\circ} \mathrm{C}$ durante $1 \mathrm{~h}$, resfriar até temperatura ambiente e pesar (tratado). Carbonizar esta amostra em mufla a temperatura inicial de $220^{\circ} \mathrm{C}$ em seguida incinerar entre $550{ }^{\circ} \mathrm{C}$ a $570{ }^{\circ} \mathrm{C}$, promovendo a evaporação da água, de substâncias voláteis e a oxidação da matéria orgânica (DE SOUZA et al., 2016).

Cálculo

$$
\text { Cinzas }(\%)=(P f-P i) \times 100 \div P
$$

$\mathrm{P}_{\mathrm{f}}=$ Peso do resíduo final do cadinho

$\mathrm{P}_{\mathrm{i}}=$ Peso inicial do cadinho

$\mathrm{P}=$ Peso da amostra (g).

\subsubsection{Proteínas Totais}

O método de Kjeldahl é executado em três principais etapas: digestão da amostra, destilação do nitrogênio e titulação. A análise foi realizada em duplicata, contendo em média 0,2 g de amostras do nibs amazônico, seguido do acondicionamento dessas em papel filtro e introduzidos nos tubos de ensaio para dar início a digestão, destilação e titulação (AOAC 2005).

\section{Cálculo}

$$
\text { Nitrogênico }(\%)=(V a-V b) \times F c \times 14 \times 100 \div A \times 1000
$$$$
\text { Proteína }(\%)=(\%) N \times 6,25
$$

$\% \mathrm{~N}=$ Teor de nitrogênio total

$\mathrm{Va}=$ volume gasto na titulação da amostra

$\mathrm{Vb}=$ volume gasto na titulação do branco

$\mathrm{M}=$ Molaridade da solução de $\mathrm{HCl}$

$\mathrm{Fc}=$ Fator de correção da solução de $\mathrm{HCl}$

$\mathrm{A}=$ massa de amostra

\subsection{DETERMINAÇÃO DE}

HMF

\section{(Hidroximetilfurfural)}

O procedimento deu-se segundo a metodologia do Instituto Adolfo Lutz (2008). Foram preparadas três soluções: Carrez I $(1,5$ g de Ferrocianeto de Potássio/50 mL), Carrez II (3 g de Acetato de Zinco/50 mL) e uma solução de Bissulfito de Sódio a 0,2 \%. Pesou-se 10,0 g do nibs do cacau e seguiu para a homogeneização da amostras em $25 \mathrm{ml} \mathrm{de}$ água e posterior extração dessa solução, em balão volumétrico $100 \mathrm{~mL}$.

Em um erlenmeyer estéril adicionou-se 0,5 mL da solução de Carrez I mais $0,5 \mathrm{~mL}$ de solução de Carrez II e completou-se o volume com água destilada seguido da homogeneização deste e transferiu-se a solução preparada para um balão volumétrico com tampa.

Filtrou-se a solução, descartou-se os primeiros $40 \mathrm{~mL}$ em um erlenmeyer, desse extrato previamente filtrado final, pipetou-se $5 \mathrm{~mL}$ dessa solução em dois tubos de ensaio separadamente e adicionou-se 5,0 mL de água em um dos 2 tubos e no outro tubo de ensaio não continha água e $\operatorname{sim} 5 \mathrm{~mL}$ de solução de bissulfito de sódio 0,2 de acordo com as normas (Adolfo Lutz 2008). Realizou-se a leitura da amostra contendo nibs do cacau no espectrofotômetro, na absorbância a 284 e 336 nm.

\subsubsection{Extração do HMF}

Para extração do HMF dos nibs de cacau pesouse inicialmente 10,0 g das amostras, diluídas em $25 \mathrm{~mL}$ 
de água destilada, seguido da filtração a vácuo.

Cálculo

$$
H M F\left(\frac{\mathrm{mg}}{\mathrm{Kg}}\right)=(\mathrm{A} 284-\mathrm{A} 336) \times 149,7 \times 5 \div \mathrm{P}
$$

$\mathrm{A}_{284}=$ leitura da abs a $284 \mathrm{~nm}$

$\mathrm{A}_{336}=$ leitura da abs a $336 \mathrm{~nm}$

$\mathrm{P}=$ massa das amostras $\mathrm{M}_{\mathrm{C} 1}$ e $\mathrm{M}_{\mathrm{C} 2} \mathrm{em}(\mathrm{g})$

$5=$ massa nominal da amostra

$149,7=(126 / 16830) *(1000 / 10) *(1000 / 5)$

\subsection{DETERMINAÇÃO FENÓLICOS TOTAIS}

Foi determinado pelo método proposto por Singleton et al., (1999). Foram pesadas 10,0 g do (nibs) e extraído em solução de metanol aquoso $50 \%$ durante \pm 1 h. A solução foi filtrada e centrifugada e logo em seguida armazenada em balão volumétrico. A quantidade total de fenóis de cada extrato contendo amostras do cacau foi quantificada mediante a curva padrão preparada com ácido gálico na concentração 10 mg.mL $\mathrm{mL}^{-1}$. Em um tubo de ensaio foi acrescentado 2,5 $\mathrm{mL}$ de solução aquosa a $10 \%$ do reativo FolinCiocalteau e 2,0 mL de carbonato de sódio a 7,5 \%, o tubo foi incubado em banho maria a $50{ }^{\circ} \mathrm{C}$ por 5 min e logo após o resfriamento do tubo de ensaio, foi iniciada a leitura do analíto a $750 \mathrm{~nm}$. O padrão da análise é realizado em diferentes concentrações de ácido gálico diluído após leitura no equipamento espectrofotômetro, figura 5 .

Cálculo

Fenólicos (mg. AG.g -1$)=\mathrm{Y}=\mathrm{a}+\mathrm{bx}$

$\mathrm{Y}=\mathrm{Abs} \mathrm{da}$ amostra

$\mathrm{x}=$ Fenóis equivalente ao padrão (ácido gálico)

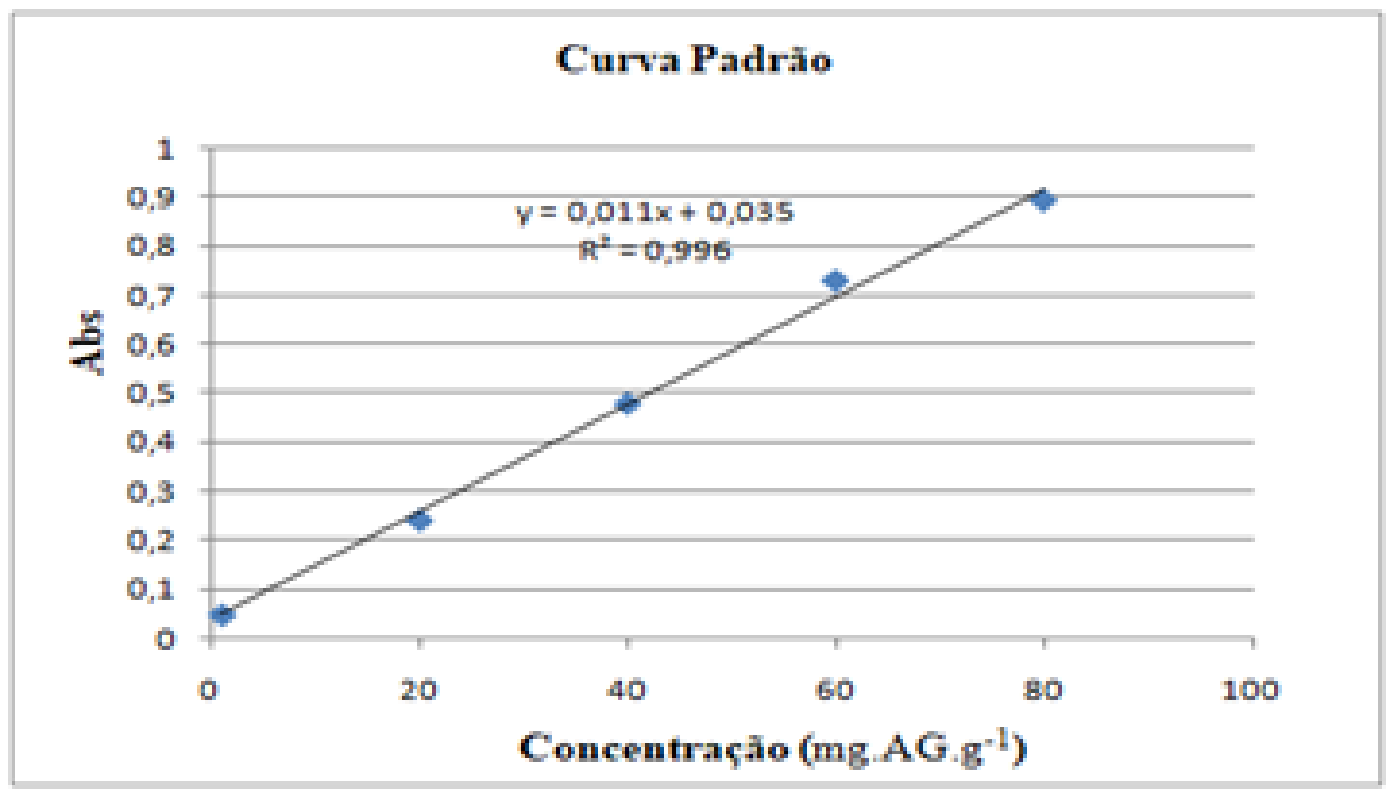

FIGURA 5 - Curva padrão de ácido gálico.

\subsection{ATIVIDADE ANTIOXIDANTE}

A metodologia para a determinação da atividade antioxidante realizada no nibs de cacau foi determinada mediante a captura ou redução do radical livre - ABTS produzido pela oxidação do 2,2 - azinobis (3-etilbenzotiazolina-6-ácido sulfônico)
(EMBRAPA 2007; BRITO 2013). O ABTS $^{+}$reage com um doador de átomos hidrogênio, como por exemplo, os compostos fenólicos, sendo convertido em uma forma incolor de ABTS. A quantidade de ABTS $^{+}$ reduzido, na reação com compostos fenólicos da amostra é expressa em equivalentes de Trolox (curva 
padrão), figura 6, foi utilizado o álcool etílico, como branco, para calibrar o espectrofotômetro, onde, esse valor foi designado o parâmetro da TEAC, capacidade antioxidante equivalente ao Trolox.

\subsubsection{Obtenção do extrato}

Foram pesados 10,0 $\mathrm{g}$ dos nibs das amêndoas e adicionados 40,0 $\mathrm{mL}$ de metanol $50 \%$, homogeneizado em agitador magnético por $15 \mathrm{~min}$, e deixado em repouso por 60 min, seguido da filtração a vácuo onde, o filtrado foi levado a um balão volumétrico $100 \mathrm{~mL}$. Foram adicionados $40,0 \mathrm{~mL}$ de acetona $70 \%$, e o volume completado com $100 \mathrm{~mL}$ de água destilada, e posteriormente efetuada leitura das absorbâncias em espectrofotômetro em comprimento de onda de 734 nm.

Para análise da capacidade antioxidante equivalente ao trolox (TEAC), a partir do extrato obtido no item anterior, foram preparadas em tubos de ensaio, três diluições diferentes, em triplicata. Em ambiente escuro, foi transferida uma alíquota de $30 \mu \mathrm{L}$ de cada diluição do extrato para tubos de ensaio com 3,0 $\mathrm{mL}$ do radical $\mathrm{ABTS}^{+} \mathrm{e}$ homogeneizados em agitador de tubos. Foi realizada a leitura desses extratos na absorbância de $734 \mathrm{~nm}$, após 6 minutos de repouso (EMBRAPA 2007). A curva padrão Trollox foi realizada de acordo com a figura 6 para obter o resultado final.

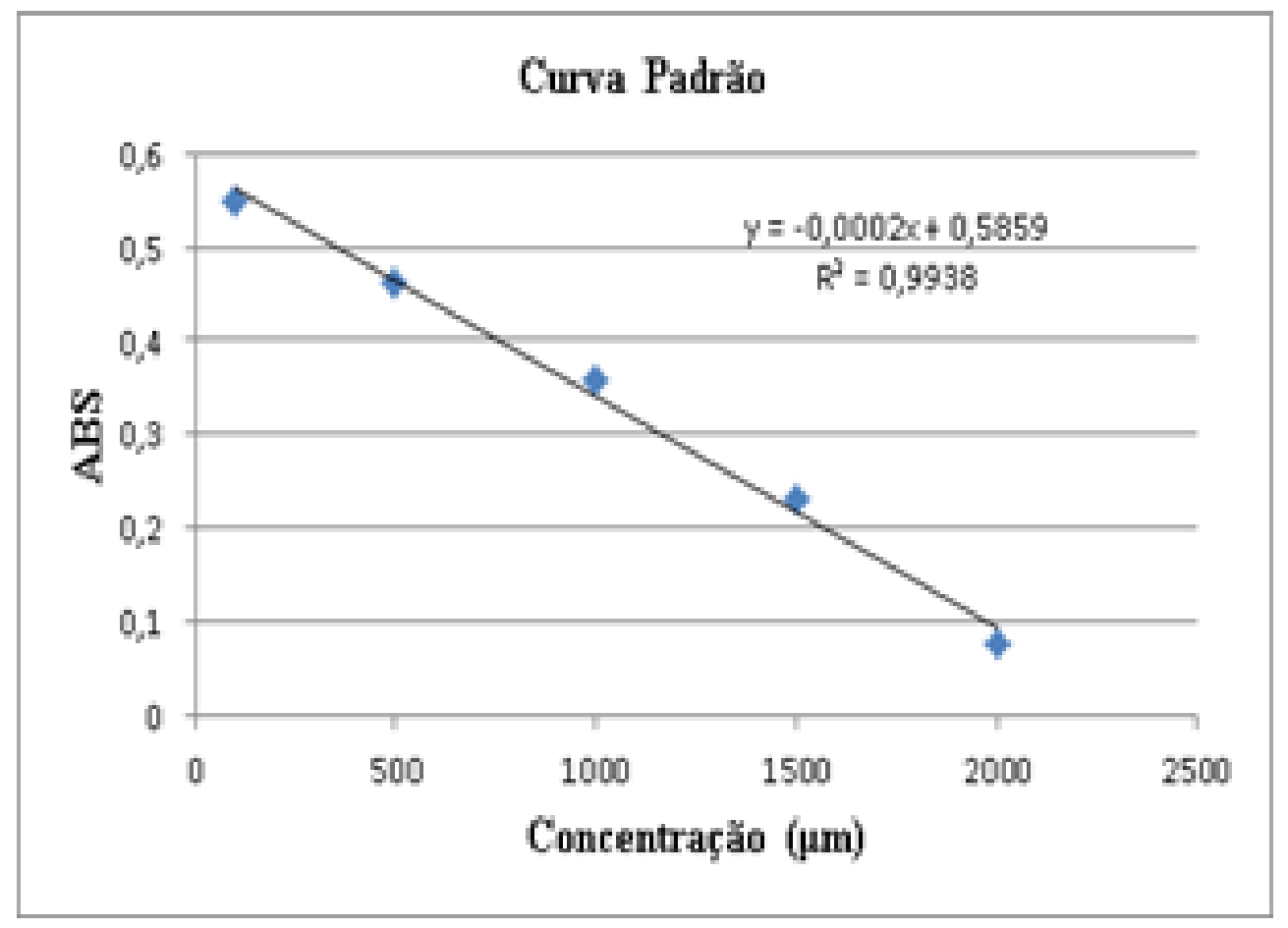

FIGURA 6 - Curva padrão de Trolox.

\section{RESULTADOS E DISCUSSÃO}

\subsection{Prova de Corte}

A INSTRUÇÃO NORMATIVA No 38 , DE 23 DE JUNHO DE 2008, do MAPA (Ministério da Agricultura, Pecuária e Abastecimento), estabelece o Regulamento Técnico da Amêndoa de Cacau, definindo o seu padrão oficial de classificação, com os requisitos de identidade e qualidade. Os resultados contidos na tabela 2 expressam o índice quanto à mensuração da qualidade final das amêndoas após a prova de corte mediante o rompimento destas ao meio, no final da etapa da secagem, onde resultaram em $90 \%$ 
destas amêndoas advindas de uma aplicação correta da etapa de fermentação, ou seja, apresentaram cotilédones marrons.

Tabela 2 - Resultado da análise física: Prova de corte das amêndoas de cacau.

\begin{tabular}{ll}
\hline Classificação & Proporção (\%) \\
Bem Fermentadas & 90 \\
Violetas & 0 \\
Achatadas & 10 \\
\hline
\end{tabular}

\subsection{Obtenções do inóculo das leveduras}

A contagem média das células leveduriformes naturais isoladas da fermentação inicial $\left(f_{1}\right)$ foi de $1,3 \mathrm{x}$ $10^{3} \mathrm{UFC} / 25 \mathrm{~g}$, resultado esse semelhante ao encontrado por SERRA et al., (2016), que foi de 1,3 x 103 UFC/20 $\mathrm{g}$ de leveduras no quarto dia de fermentação. A presença dessas células se deu nas primeiras 12, 24 e 48 h em condição aeróbia e anaeróbia, o que permitiu ratificar que as células leveduriformes são anaeróbias facultativas, pois só há a incorporação de oxigênio na massa após o $2^{\circ}$ dia de fermentação, essas colônias tem aspecto cremoso, algumas são médias, outras pequenas, variam também na cor, creme, pink, verde neon, esses resultados adequam-se aos encontrados por GUTIÉRREZ (2007), OLIVEIRA (2015), MIGLIARI (2001) e SOUZA, et al., (2012) quando mencionam ter identificado colônias isoladas de leveduras de cor branca, creme e em menor proporção rosadas, cremosas e regulares.

As evidências do crescimento de leveduras no caldo alternativo se deve à formação e desprendimento de gás $\left(\mathrm{CO}_{2}\right)$, odor de fermento e sedimentação também foram notados nos tubos de ensaio após a incubação, esses resultados corroboram para com os estudos sobre o crescimento e multiplicação desse fungo, além das principais características e produção de metabólitos de acordo com SILVA et al., (2017); AMORIM (2005).

$\mathrm{O}$ exsudado contido nas formulações dos caldos alternativos apresentaram $\mathrm{pH}$ 3,3 e segundo
GARCÍA e MORETA (2013) e MENDOZA (1997) esse resíduo possui ótima disponibilidade para carboidratos e pectina, além de que o pH encontrado está próximo ao mencionado por EFRAIM (2004) e SILVA (2002) que concluíram em seus estudos que bolores e leveduras desenvolvem-se melhor no ambiente com $\mathrm{pH}$ menor que 4,5 e valores de $\mathrm{pH}$ próximos de 3,6 auxiliam para uma ótima atividade leveduriforme.

Foram observadas diferenças nos aspectos morfológicos e microscópicos dessas células, após incubação das placas contendo ágar DRBC, tanto nos isolados iniciais $\left(f_{1}\right)$ e finais $\left(f_{2}\right)$ que poderia ter sido possível a identificação das espécies se houvesse cartelas para realizar a leitura de identificação no equipamento. $\mathrm{O}$ resultado apresentado reitera os encontrados nos estudos de NELSON e COX (2014) e BARROS (2013), em que as leveduras se reproduzem sexualmente, pela fusão de duas células, portanto, no período final da fermentação inicial ao isolar a levedura desse processo pode ocorrer que essa seja diferente daquela isolada ao final da fermentação otimizada, dessa forma, se ela tiver uma boa capacidade fermentativa, poderá ser a cepa adequada para o melhoramento do processo de fermentação das sementes, visto que o emprego de fermentos previamente selecionados é direcionado a elucidar a fermentação lenta, ou seja, poderá acelerar essa etapa, ocasionando a diminuição do tempo final, proporcionando produtos com qualidade mais uniforme, visto que o desempenho do processo de fermentação é afetado pelo tipo de levedura atuante.

\subsection{Otimização do beneficiamento das sementes} de cacau

A tabela 3 apresenta os resultados da formação do exsudado nos dois primeiros dias de fermentação em todos os ensaios, entretanto, quando inserido o 
coquetel start, a formação do exsudado se deu até o terceiro dia, o mesmo foi observado por OLIVEIRA (2015) que reporta em seus trabalhos que a drenagem do mel do cacau foi eficiente nas primeiras $24 \mathrm{~h}$ de fermentação, porém em 48 h o volume de mel foi muito inferior quando comparado aos outros tratamentos com o inóculo.

Nota-se que o teor de SST máximo do exsudado foi de 23,0 oBrix. Estando este resultado entre os valores apontados por GARCÍA e MORETA (2013) e AVENDAÑO (2018) que encontraram SST de 15,0 ${ }^{\circ}$ Brix e $18{ }^{\circ}$ Brix. Observa-se que os valores de $\mathrm{pH}$ determinados estão no intervalo de 3,2 a 3,74 o que permite inferir que a fermentação aconteceu por conta da oscilação desses valores no pH. Estes resultados são similares aos encontrados por AVENDAÑO (2018), LLERENA (2016) e GARCÍA e MORETA (2013) que apresentam valores médios de 3,5, 3,85 e 3,59, respectivamente.

\begin{tabular}{lllll}
\hline Ensaios & Tempo (dias) & Temperatura $\left.\mathbf{~}^{\mathbf{0}} \mathbf{C}\right)$ & SST* $\left.^{\mathbf{o}}{ }^{\mathbf{B}} \mathbf{B r i x}\right)$ & $\mathbf{p H}$ \\
$f_{1}$ & 0 & 30 & 20 & 3,2 \\
$f_{1}$ & 1 & 39 & 10 & 3,31 \\
$f_{2}$ & 29 & 23 & 3,74 \\
$f_{2}$ & 0 & 28 & 20 & 3,21 \\
$f_{2}$ & 1 & 24 & 0 & - \\
\hline
\end{tabular}

Legenda: $f_{1}$ - Fermentação inicial e $f_{2}$ - Fermentação com indução do coquetel start, - (não foi realizado análise), *Sólidos Solúveis Totais.

\subsection{Fermentações sem inóculo $\left(f_{1}\right)$ e com inóculo} $\left(f_{2}\right)$

É possível observar na figura 7 e 8 o perfil da temperatura da massa de cacau monitorada em fermentador sustentável $\left(f_{1}\right)$. Percebe-se que a temperatura inicial do processo fermentativo é de $29^{\circ} \mathrm{C}$ e a temperatura máxima de $39{ }^{\circ} \mathrm{C}$ no segundo dia e houve o declínio para $38^{\circ} \mathrm{C}$ no terceiro dia e mantevese constante a $31{ }^{\circ} \mathrm{C}$ até finalizar o processo após sete dias de fermentação das sementes. Estes resultados assemelham-se aos obtidos nos estudos de SANTOS (2010), em que a fermentação também apresentou aumento da temperatura com 48 horas de fermentação, e manteve-se constante até o fim do processo. Em estudos feitos por BRITO (2013) durante sete dias de fermentação, as temperaturas iniciais e finais atingiram 22,1 e $34,0^{\circ} \mathrm{C}$, respectivamente. No entanto, SERRA e colaboradores (2016) reportaram que a temperatura inicial da fermentação de cacau estabeleceu-se em torno de $29{ }^{\circ} \mathrm{C}$.

A temperatura inicial do processo fermentativo feito com coquetel start $\left(f_{2}\right)$ foi de $23{ }^{\circ} \mathrm{C}$, com aumento da temperatura no primeiro dia atingindo $29{ }^{\circ} \mathrm{C}$, seguido do declínio desta até o quarto dia de fermentação, e máxima de $30{ }^{\circ} \mathrm{C}$ no quinto dia. Resultados similares foram encontrados por OLIVEIRA (2015), no qual, os autores utilizaram cultura start no processo fermentativo do cacau na Bahia, e obtiveram aumento da temperatura no primeiro dia de fermentação.

A elevação da temperatura na fermentação $\left(f_{2}\right)$ logo no primeiro dia é resultado do intenso consumo dos substratos componentes das sementes pela atividade das leveduras adicionadas, o que não se observou na fermentação $\left(f_{1}\right)$, onde, a elevação da temperatura aconteceu após o segundo dia, dessa forma, podemos inferir que houve a diminuição da fase de adaptação das leveduras selecionadas, uma vez que essas estavam mantidas em caldo nutritivo na sua faixa ótima de pH e que o declínio dessa atividade se deve ao aumento da produção de álcool que atua como substrato para os demais microrganismos que se utilizam do subproduto expelido pelas leveduras como fonte de obtenção de energia. 

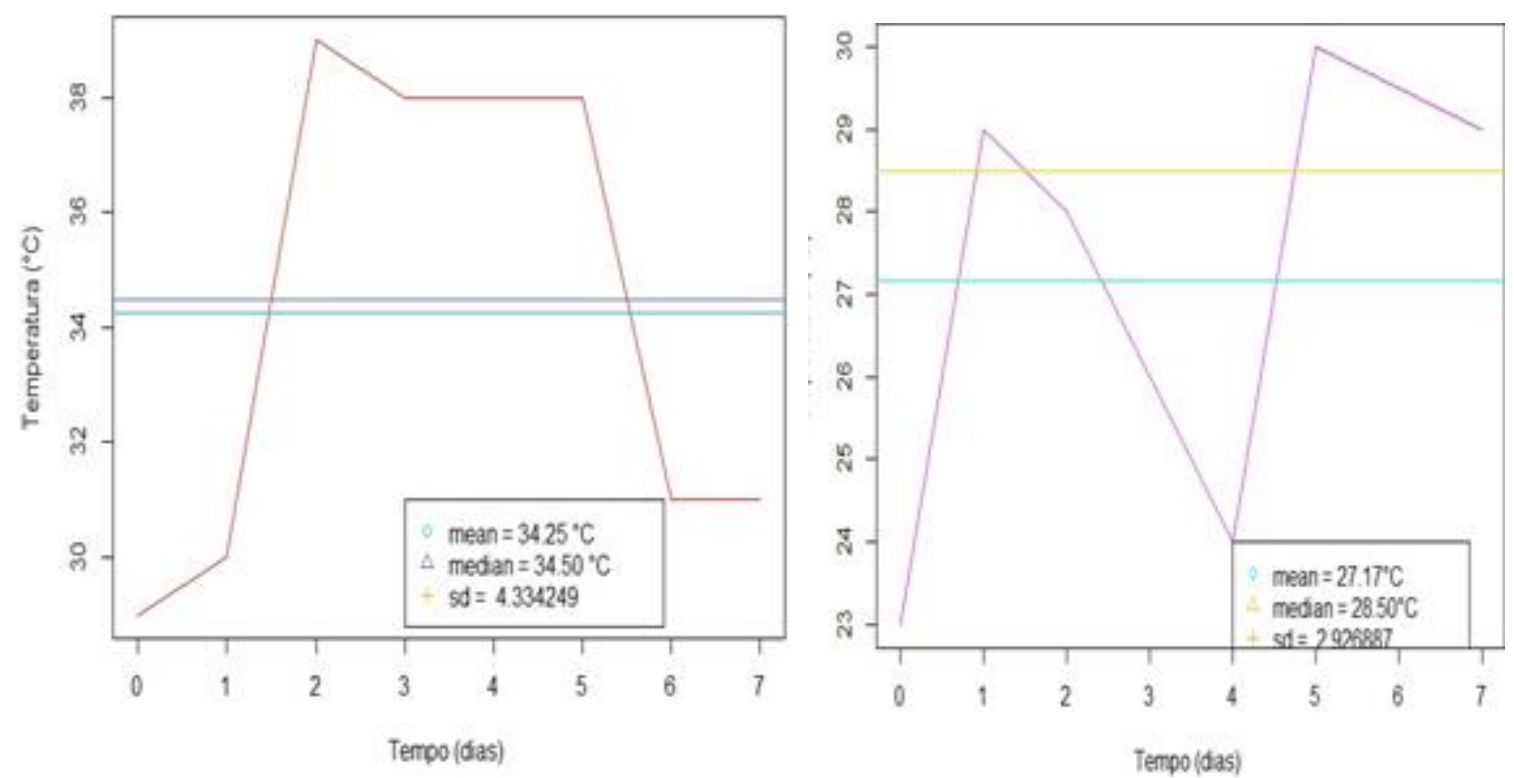

FIGURAS 7 E 8 - Média e desvio padrão da temperatura de fermentação monitorada em fermentador sustentável para os ensaios $\left(f_{1}\right)$ e $\left(f_{2}\right)$.

O acompanhamento do $\mathrm{pH}$ e a curva do teor de Sólidos Solúveis Totais em função do tempo de fermentação, sem inóculo e com inóculo, está apresentado na figura 9 e 10. Para as amêndoas do processo fermentativo $\left(f_{1}\right)$, o $\mathrm{pH}$ inicial e final foi de 4,20 e 5,26, respectivamente, estando entre os valores observados por CRUZ (2012), que foi de 4,1 para pH inicial e pH 5,0 ao final do processo da fermentação. SANTOS (2013), mostrou em seu estudo que no início da fermentação, o pH foi de 6,4 com quedas no quarto e sétimo dia de fermentação, atingindo valores de $\mathrm{pH}$ 5,2 e 5,7, respectivamente.

As amêndoas de cacau apresentaram teor de sólidos solúveis totais no tempo inicial e final de 20,0 e 1,0 ${ }^{\circ}$ Brix. Esses resultados estão entre os obtidos por
EFRAIM (2004) no decorrer do primeiro e segundo dia com valores médios de 22,11 e 19,07 ${ }^{\circ}$ Brix. O ensaio para a fermentação com inóculo start, obteve $\mathrm{pH}$ inicial de 5,02, ocorrendo a diminuição para 4,71 no primeiro dia e aumento para $\mathrm{pH}$ 6,3 no sétimo dia. O teor de sólidos solúveis inicial das amêndoas para o ensaio final $\left(f_{2}\right)$ esteve a $16^{\circ}$ Brix com queda após o segundo dia para 2,5 e finalizando a $0{ }^{\circ}$ Brix no quinto dia, esses resultados significam que após as análises realizadas nas amostras durante a monitoração da fermentação esses são indicativos de que a fermentação foi efetuada e aplicada de forma potencialmente eficiente, pois houve o decréscimo total do SS durante a etapa de fermentação. 

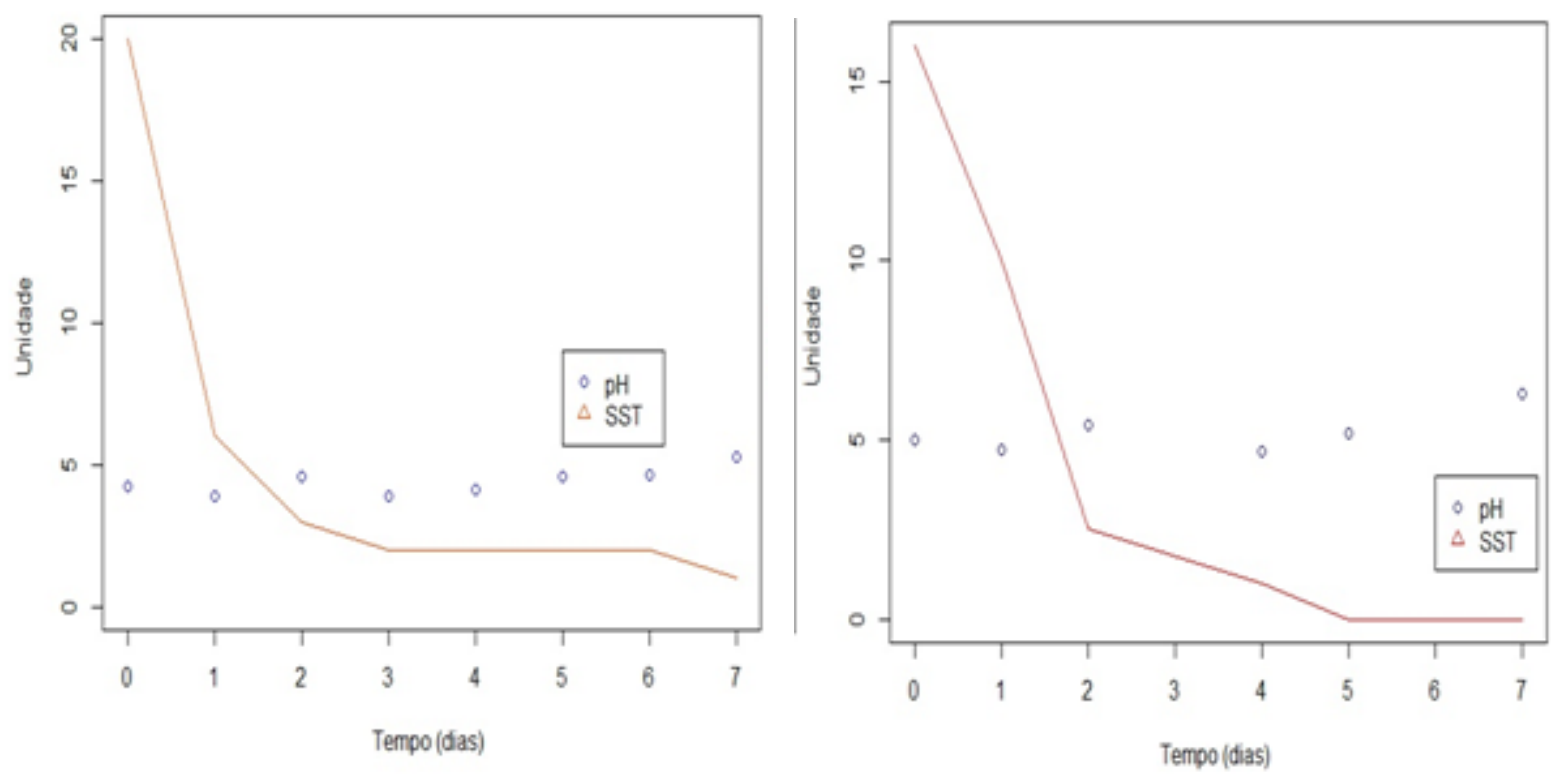

FIGURA 9 E 10 - Valores médios dos parâmetros Físico-Químicos (pH e SST*) no processo fermentativo monitorado em fermentador sustentável para os ensaios $\left(f_{1}\right)$ e $\left(f_{2}\right)$. *Sólidos Solúveis Totais.

Através dos parâmetros físico-químicos monitorados durante a fermentação com inóculo start $\left(f_{2}\right)$ podemos concluir que houve elevação da temperatura de $23{ }^{\circ} \mathrm{C}$ para $29{ }^{\circ} \mathrm{C}$ concomitante a redução do pH de 5,02 para 4,71, logo no primeiro dia de fermentação, enquanto que na fermentação sem inóculo $\left(f_{1}\right)$ esse declínio foi somente observado após o segundo dia de processo. Portanto, a redução do tempo de fermentação com inóculo $\left(f_{2}\right)$ pode ser também evidenciado juntamente ao aumento do $\mathrm{pH}$ de 4,70 para 5,19 , referente ao quarto e quinto dia de fermentação além de expressar a redução no teor de SST para 0,0 ${ }^{\circ}$ Brix e diminuição da temperatura máxima de $30^{\circ} \mathrm{C}$.

A tabela 4 apresenta os resultados quanto às análises aplicadas nos nibs obtida após cominuição das amêndoas processadas $\left(\mathrm{Mc}_{1}\right.$ e $\left.\mathrm{Mc}_{2}\right)$. $\mathrm{O} \mathrm{pH}$ médio de 5,38 encontrados estão em consonância ao pH médio apontado nos estudos realizados por DE OLIVEIRA (2013); LEITE (2012) e DA SILVA (2011) que variou de 5,0 a 5,40, as diferenças observadas no $\mathrm{pH}$ podem ser justificadas pelas condições edafoclimáticas do fruto de origem. A gordura corresponde à fração do alimento solúvel em solventes orgânicos e inclui diferentes classes de substâncias DE SOUZA et al., (2016), nestes ensaios as amêndoas apresentaram teor médio de 29,33 $\%$ de lipídios, estando próximo a média apresentada por RIBEIRO (2014) de 31,0 \% de lipídeos.

A média para o teor de proteína do nibs $\left(\mathrm{Mc}_{1} \mathrm{e}\right.$ $\mathrm{Mc}_{2}$ ) foi de 16,08 \%, onde a maior porcentagem encontrada foi no nibs resultante do beneficiamento com inóculo de cepas leveduriformes, estando este resultado acima do exposto por EMBRAPA (2003); RIBEIRO (2014) e NOGUEIRA (2015) no líquor de cacau com 12,27 \% e 15,53 \% de proteínas, respectivamente, esse foi um dos parâmetros positivos para a fermentação com inóculo, pois obteve nibs com maior porcentagem de proteína. A média para cinzas esteve a $1,72 \%$, resultado próximo ao mencionado por EMBRAPA (2003) que foi de 2,13\% de cinzas em base seca.

Podemos concluir a partir dos resultados nos parâmetros bioquímicos abaixo que o melhoramento da fermentação do cacau mediante a inserção de cepas starts metabolicamente selecionada a partir do cultivo em extrato contendo caldo alternativo se torna viável, pois, resulta em nibs com características mais relevantes, 
não só no flavor, mas também, bioquímico. A concentração média para HMF que possui relação com a despigmentação das amêndoas e formação de malanoidinas via ação de enzimas especificas foi de 2,69 (mg/Kg), corrobora com o estudo de RIBEIRO (2014) que apresentou 2,68 (mg/Kg).

Os compostos fenólicos são os produtos do metabólito secundário das plantas e possuem na sua estrutura pelo menos um anel aromático ligado a um ou mais grupos hidroxila (SANTOS 2013). Os valores encontrados na determinação dos compostos fenólicos totais no ensaio sem inóculo foi de 127,3 (mg.AG.g-1) já na fermentação com inóculo $\left(\mathrm{Mc}_{2}\right)$ foi elevada de 331,5 (mg.AG. $\mathrm{g}^{-1}$ ) resultado este superior ao encontrado por PIMENTEL (2016) no "nibs" de cacau, em que os valores variam entre 125 e 168 (mg AG. $\mathrm{g}^{-1}$ ), com isso, o ensaio efetuado contribuiu para com um aumento da concentração de compostos fenólicos quando comparados com os valores advindo dos nibs do beneficiamento convencional.

Às espécies reativas do oxigênio são importantes nos processos fisiológicos como na produção de energia podendo vir até compor produtos fármacos. O efeito antioxidante se deve a um conjunto heterogêneo de substâncias formadas por vitaminas, minerais, pigmentos, enzimas e outros compostos vegetais que bloqueiam o efeito danoso dos radicais livres, no qual, os ácidos ascórbicos e compostos fenólicos são antioxidantes hidrofílicos e os carotenóides, antioxidante lipofílico (EMBRAPA 2007).

O resultado da análise para a capacidade antioxidante nos extratos do nibs com inóculo start $\left(\mathrm{Mc}_{2}\right)$ 148,5 $\mu \mathrm{mol}$.Trollox/g foi superior ao encontrado na fermentação sem inóculo 128,2 $\mu \mathrm{mol}$.Trollox/g, este resultado se apresenta levemente acima do mencionado por SALVADOR (2011) em cacau geneticamente modificado que foi de 141,27 $\mu$ mol.Trollox.g-1 ${ }^{-1}$
Tabela 4 - Caracterização Centesimal dos nibs cominuídos em Sire Cutter

\begin{tabular}{lll}
\hline Análises & $\mathrm{Mc}_{1}$ & $\mathrm{Mc}_{2}$ \\
$\mathrm{pH}$ & 5,1 & 5,67 \\
Lipídios (\%) & 32,96 & 25,70 \\
Proteína (\%) & 14,72 & 17,45 \\
Cinzas (\%) & 2,27 & 1,17 \\
HMF (mg/Kg) & 2,52 & 2,87 \\
Fenólicos (mg.AG.g- & 127,3 & 331,5 \\
${ }^{1}$ ) & & \\
ABTS & 128,2 & 148,5 \\
( $\mu$ mol.Trollox.g) & & \\
\hline
\end{tabular}

Legenda: $\mathrm{Mc}_{1}$ : Fermentação inicial; $\mathrm{Mc}_{2}$ : Fermentação com indução do coquetel start.

A partir dos resultados explanados na tabela acima, podemos concluir que o processo executado mediante os ensaios discutidos apresentou-se efetivo para a maioria dos parâmetros analisados nos nibs das amêndoas fermentadas com coquetel start $\left(f_{2}\right)$, pois foram maiores que os nibs do ensaio inicial $\left(f_{1}\right)$ para os parâmetros: Proteínas, HMF, Fenólicos Totais e Determinação da atividade antioxidante, ou seja, o ensaio da fermentação com inóculo proposto nesse estudo mostrou-se potencialmente responsável por intensificar além do flavor, elevar a disponibilidade dos parâmetros bioquímicos do produto final advindo do beneficiamento realizado neste.

4.5 Perfil da Umidade das amêndoas na Fermentação

A umidade inicial das amêndoas no ensaio $\left(f_{1}\right)$ alcançou 53,70\% e final 3,5\% na fermentação com inóculo $\left(f_{2}\right)$ a umidade inicial e final, respectivamente, foi de $21,51 \%$ e 9,82 \%, o resultado inicial está abaixo do mencionado por SANTOS (2013) cuja umidade inicial dos cotilédones de cacau esteve a 33,88\%. O resultado final está próximo aos padrões estabelecidos pela CEPLAC (2011) em 7 a $8 \%$ a umidade das amêndoas.

\section{CONCLUSÃO}

A inserção do fermentador sustentável e do coquetel de cepas previamente cultivadas e isoladas em 
caldo alternativo foram inovadores, pois foi proposto recursos para atingir o acréscimo da qualidade final das amêndoas concomitante a agregação de valor $\mathrm{e}$ diversidade na oferta de co-produtos da cadeia produtiva do cacau. O experimento foi eficiente, pois ocorreu a tendência na curva para a redução do tempo da fermentação de sete para cinco dias, sustentado com aumento da temperatura logo nas primeiras 24 horas de inicio do processo fermentativo das amêndoas, houve o aumento do pH e também diminuição do SST após $96 \mathrm{~h}$ no quinto dia de fermentação além de obter nibs de cacau com disponibilidades bioquímicas potencialmente mais preferíveis que quando comparado aos nibs resultantes do ensaio do beneficiamento convencional, aplicado por produtores tradicionais em campo.

\section{REFERÊNCIAS}

ALMEIDA, C, ROCHA, J, CARITÁ, J, SOUZA, T, SOUZA, PV. Biotecnologia na Produção de Alimentos (DOSSIÊ TÉCNICO). São Paulo: Universidade de São Paulo; 2011.p.1-37.

AMORIM, HV. Fermentação alcoólica: ciência \& tecnologia. Fermentec. Embrapa: Agropecuária Oeste (CPAO). Piracicaba; 2005.

ASSOCIATION OF OFFICIAL ANALYTICAL CHEMISTS (AOAC). Official methods of analysis.18th ed. Gaithersburg, M.D, USA; 2005.

AVENDAÑO, EJV. "AISLAMIENTO Y SELECCIÓN DE LEVADURAS NATIVAS CAPACES DE PRODUCIR ALTOS RENDIMIENTOS DE ALCOHOL EMPLEANDO COMO SUSTRATO EL EXUDADO DE CACAO (Theobroma cacao L.) CLON CCN-51 EN EL DISTRITO DE SAN ALEJANDRO". PUCALLPA: UNIVERSIDAD NACIONAL DE UCAYALI; PERÚ; 2018.p.1-110.

\section{http://181.176.160.68/bitstream/handle/UNU/3868 $\angle 000003526$ T.pdf? sequence $=1 \&$ is Allowed $=\mathrm{y}$}

BARROS, AP. Influência da cepa de levedura na composição fenólica e aromática de vinhos da cv. Syrah no vale do sub médio são Francisco (Dissertação de mestrado). Florianópolis: Universidade de Santa Catarina; 2013.p.1-96. https://repositorio.ufsc.br/handle/123456789/ $\underline{107607}$

BRASIL. Ministério da Agricultura, Pecuária e Abastecimento - Instrução Normativa $n^{\circ} 57$, de 12 de nov. de 2008. Regulamento Técnico da Amêndoa de Cacau. Diário Oficial da União, Brasília, 13 nov. 2008. Seção I, pg.2.

BRITO, BDNDC. Aminas bioativas e compostos fenólicos no cacau (Theobroma cacao L.): influência do processo de fermentação (Dissertação de mestrado). Belém-PA: Universidade Federal do Pará; 2013.p.1-37. http://ppgcta.propesp.ufpa.br/ARQUIVOS/di ssertacoes/2013/Brenda $\% 20$ Brito PPGCTA.p $\underline{\mathrm{df}}$

CAVALCANTE, P. "Frutas comestíveis na Amazônia". Belém-PA: Museu Paraense Emílio Goeldi. $7^{\circ} \mathrm{Ed} ; 2010$.

COHEN, KO, LUCCAS, V, SOUSA, MV, JACKIX, MNH. Processamento tecnológico das amêndoas de cacau e de cupuaçú. Belém-PA: Embrapa Amazônia Oriental; 2003.p.1-36. https://www.infoteca.cnptia.embrapa.br/handl e/doc/406024

CRUZ, J. Caracterização das sementes de variedades de cacau Theobroma cação L. resistentes à vassoura de bruxa durante a fermentação e após a secagem (Dissertação de mestrado). BAHIA: Universidade Federal da Bahia; 2012.p.1-102.

http://www.repositorio.ufba.br:8080/ri/bitstream/ri/ 8794/1/Jaqueline $\% 20$ Fontes $\% 20$ Moreau $\% 20 \mathrm{C}$ ruz.df

DA SILVA, I. Enterobactérias na cadeia produtiva do cacau ao chocolate (Dissertação de mestrado). CAMPINAS: Universidade Estadual de Campinas; 2011.p.1-101.

http://repositorio.unicamp.br/jspui/handle/REPOSI $\underline{\mathrm{P} / 254595}$

DE SOUZA, G, SOBRINHO, R, BOZA, Y, OLIVARES, Y, PACCES, V. Validação de métodos para análise de alimentos: enfoque em análise centesimal. São Paulo; Editora: 
REMESP. $\quad$ Ed. $1^{\circ} ; \quad$ 2016.p.1-124. https://www.crq4.org.br/sms/files/file/livro v alida metodos alimentos 2018.pdf

DIAZ, A. Sucessão microbiana durante a fermentação espontânea do cacau para a caracterização e isolamento de linhagens starter (Dissertação de mestrado). Ilhéus/Bahia: Universidade Estadual de Santa Cruz; 2016.p.1-54

http://nbcgib.uesc.br/genetica/admin/images/files/ Alberto $\% 20$ Montejo $\% 20 \mathrm{Diaz} \% 20 \% 20 \mathrm{com} \% 20$ ficha.pdf

DE OLIVEIRA, IF. "Avaliação e adequação do comportamento de gorduras equivalentes de manteiga de cacau para chocolates" (Dissertação de mestrado). CAMPINAS: Universidade Estadual de Campinas; 2013.p.1-101.

http://repositorio.unicamp.br/jspui/handle/REPOSI $\underline{\mathrm{P} / 254677}$

DEUS, Wl. Influência dos métodos de secagem nas propriedades antioxidantes de cacau (Theobroma cacao L.) (Dissertação de mestrado). BAHIA: Universidade Federal da Bahia; 2015.p.1-45. http://www.pgalimentos.far.ufba.br/sites/pgali mentos.far.ufba.br/files/dissertacao_valterney deus.pdf

EFRAIM, P. Estudo para minimizar as perdas de flavonóides durante a fermentação de sementes de cacau para produção de chocolate (Dissertação de mestrado). CAMPINAS: Universidade Estadual de Campinas; 2004.p.1126.

http://taurus.unicamp.br/bitstream/REPOSIP L255238/1/Efraim Priscilla M.pdf

GARCIA, SV, MORETA, FA. Optimización y aprovechamiento Del resíduo exudado Del mucílago de La almendra fresca Del cacao (Theobroma cacao L.) CCN 51 En La Elaboracion de Vinagre. Revista de Investigacion Científica. 2013.p.1-12.

https://revistas.ute.edu.ec/index.php/tsafiqui/ article/view/256/260

GUTIÉRREZ, LAU. Caracterización fisiológica de levaduras aisladas de La filósfera de mora. Colômbia: Bogotá; Pontificia Universidad Javeriana; 2007.p.1-154.

https://javeriana.edu.co/biblos/tesis/ciencias/tesis27 6.pdf

INSTITUTO ADOLFO LUTZ. Normas analíticas do Instituto Adolfo Lutz: Métodos físico-químicos para análise de alimentos. São Paulo; 2008.

IMBERTI, RM. Estudo da secagem artificial de amêndoas de cacau visando ao aproveitamento na indústria de chocolate: otimização estrutural do processo e eficiência energética (Dissertação de mestrado). SÃO MATEUS: Espirito Santo; Universidade Federal do Espírito Santo; 2017.p.1-98.

http://repositorio.ufes.br/bitstream/10/8436/1/tese $1083250-$ Rodrigo\%20Mazolini\%20Imberti.pdf

LEITE, PB. Caracterização de chocolates provenientes de variedades de cacau Theobroma cacao L resistentes a vassoura de bruxa (Dissertação de mestrado). BAHIA: Universidade Federal da Bahia; 2012.p.1-170. http://www.repositorio.ufba.br:8080/ri/handle $\not$ ri $/ 8742$

LLERENA, WF. Mejoramiento Del Proceso de Fermentación Del Cacao Theobroma cacao L. Variedad Nacional y Variedad CCN51. Equador: UNIVERSIDAD INTERNACIONAL DE ANDALUCÍA; 2016.p.1-140. https://dialnet.unirioja.es/servlet/libro?codigo $\equiv 664426$

LIMA, U. Biotecnologia Industrial: Processos Fermentativos e Enzimáticos. São Paulo: Edgard Blucher LTDA, vol 3; 2001.

MAKI, CS. Diversidade e potencial biotecnológico de fungos endofíticos de cacau (Theobromacacao L.) (Doctoral dissertation). Piracicaba: Universidade de São Paulo; 2006. https://teses.usp.br/teses/disponiveis/11/1113 7/tde-06042006-172002/en.php

MENDOZA, JL. "Obtencion de pectina a partir Del exudado de cação Teobroma cacao Sp. PERU: TINGO MARIA; Universidad Nacional Agraria de La Selva 1997. http://repositorio.unas.edu.pe/bitstream/handl 
e/UNAS/339/FIA-94.pdf?sequenc

MIGLIARI, PC. Classificação das cepas de leveduras dominantes de processos fermentativos utilizando parâmetros fermentativos e taxonomia numérica (Dissertação de mestrado). Campinas: São Paulo. Universidade Estadual; 2001.

http://repositorio.unicamp.br/jspui/bitstream/ REPOSIP/267565/1/Oliveira_PatriciaCandiot oMigliari_M.pdf

NELSON, D, COX, M. Princípios de bioquímica de Lehninger. Porto Alegre. 6. ed.: Artmed, 2014.

NESPOLO, CR, PINTO, FST, OLIVERA, FC. Práticas em Tecnologia de Alimentos. Editora: Artmed, 2015.

NOGUEIRA, BL. Processamento do cacau: avaliação do teor nutricional do chocolate e dos outros derivados do cacau. Lorena: Universidade de São Paulo; 2015. http://sistemas.eel.usp.br/bibliotecas/monogra fias/2015/MBI15007.pdf

OLIVEIRA, MPM. Seleção de leveduras pectinoliticas para melhoria da fermentação do cacau (Dissertação de mestrado). Piracicaba: Universidade de São Paulo;

2015.

https://www.teses.usp.br/teses/disponiveis/11 L11138/tde-04052015-101101/pt-br.php

OETTERER, M, REGITANO-d'ARCE, MAB, SPOTO, MHF. Fundamentos de Ciências e Tecnologia de Alimentos. Barueri: Manole, 2006. 612 p.

PEREIRA, IO. Viabilidade da utilização da casca de cacau como combustível no aquecimento de ar para secagem de amêndoas de cacau (Doctor Scientiae). VIÇOSA: MINAS GERAIS. Universidade Federal; 2013. http://www.bibliotecaflorestal.ufv.br/bitstream /handle/123456789/13939/Tese Ivan-deOliveira-Pereira.pdf?sequence $=1$ \&isAllowed $=\mathrm{y}$

PIMENTEL, AA. AVALIAÇÃO DA CAPACIDADE ANTIOXIDANTE E QUANTIFICAÇ̃̃O DE CONSTITUINTES FENÓLICOS DE NIBS E CHOCOLATE DE VARIEDADES CLONAIS DE CACAUEIRO (Magister Scientiae). ITAPETINGA: BAHIA. Universidade Estadual do Sudoeste; 2016. http://www2.uesb.br/ppg/ppgecal/wpcontent/uploads/2017/04/ALEXANDRE-
PIMENTEL.pdf

PRADO, FC. Desenvolvimento de bioprocesso para produção de bebida probiótica à base de água de coco (Dissertação de doutorado). Curitiba. Universidade Federal do Paraná; 2007. https://acervodigital.ufpr.br/bitstream/handle /1884/18496/Tese\%20bebi\%5B1\%5D.pdf?seq uence $=1 \&$ is Allowed $=\mathrm{y}$

RIBEIRO, M. Avaliação do 5-hidroximetilfurfural como produto de reação de maillard durante o processo de torração de amêndoas de cacau Theobroma cacao L (Dissertação de Mestrado). Bahia. UFBA; 2014. http://www.pgalimentos.far.ufba.br/sites/pgali mentos.far.ufba.br/files/dissertacao margareth ribeiro.pdf

RIPPER, BA. Efeito da torrefação sobre a composição química das melanoidinas do café por clae-dadem e rmn e sua relação com a atividade antioxidante da bebida (Dissertação de mestrado). Universidade Federal do Rio de Janeiro; 2015. https://ppgcal.iq.ufrj.br/wpcontent/uploads/2017/06/BEATRIZ_RIPPE R.pdf

SINGLETON, VL, ORHOFER, R, LAMUELARAVENTÓS, RL. Analysis of total phenols and other oxidation substrates and antioxidants by means of folin-ciocalteu reagent. Methods in Enzymology. Volume 299, 199, Pages 152178.URL:

https://www.sciencedirect.com/science/article /pii/S0076687999990171

SANTOS, CC. Influência dos processos de fermentação e secagem no teor de compostos fenólicos e capacidade antioxidante de amêndoas de cacau amazônico (Theobroma cacau var. Forasteiro) (Dissertação de mestrado). Belém-PA. UFPA;

2013. http://ppgcta.propesp.ufpa.br/ARQUIVOS/di ssertacoes $/ 2013 /$ Caroline $\% 20$ Costa $\% 20$ Santos. pdf

SANTOS, DS. Inoculação de leveduras start na fermentação do cacau para melhoria do flavor (Dissertação de mestrado). IHÉUS-Bahia. UESC; 2010. http://livros01.livrosgratis.com.br/cp135558.p $\underline{\mathrm{df}}$

Sbravatti Junior, JA, AUER, CG, PIMENTEL, IC, SANTOS, ÁF, SCHULTZ, B. SELEÇÃO IN 
VITRO DE FUNGOS ENDOFÍTICOS PARA O CONTROLE BIOLÓGICO DE Botrytis cinerea em Eucalyptus benthamii. FLORESTA, Curitiba, PR, v. 43, n. 1, p. 145 - 152, jan./mar. 2013.

https://revistas.ufpr.br/floresta/article/view/2 $\underline{6265 / 20245}$

SERRA, JL, MOUCHRECK, AN, ROGEZ, H., DARNET, S. Quantificação de leveduras associadas a fermentação de cacau no estado do Pará. XXV Congresso Brasileiro de Ciência e Tecnologia de Alimentos. Porto Alegre - RS UFRGS; 2016. http://www.ufrgs.br/sbctarseventos/xxvcbcta/anais/files/1297.pdf

SILVA, RR, BOCHI, N, ROCHA FILHO, RC, MACHADO, PFL. Introdução à Química Experimental. Ed: 2'. Editora: UFSCAR, 2014.

SILVA, Nda, JUNQUEIRA, VCA, SILVEIRA, NFdeA, TANIWAKI, MH,GOMES, RAR, OKAZAKI, MM. Manual de métodos de análise microbiológica de alimentos e água. $5^{\circ}$ ed - São Paulo: Blücher; 2017.

SILVA, MC. Avaliação da qualidade microbiológica de alimentos com a utilização de metodologias convencionais e do sistema simplate (Dissertação de mestrado). Piracicaba-São Paulo. USP;

2002. https://teses.usp.br/teses/disponiveis/11/1114 1/tde-29102002-161542/pt-br.php

SOUZA, MD de, OTÁVIO, PF, CALDEIRA, SF, DORVAL, A, SOUSA, NJ. Desenvolvimento in vitro do fungo simbionte de Atta sexdens rubropilosa Forel, 1908 (Hymenoptera: Formicidae) em meio de cultura com diferentes extratos vegetais. Cienc.Rural [online]. 2012, vol.42, n.9, pp.1603-1609. Epub July 19; 2012.

http://www.scielo.br/scielo.php?pid=S0103$\underline{84782012000900014 \& s c r i p t=\text { sci } \text { abstract\&tlng }}$ $\equiv \mathrm{pt}$

VIEIRA, DG, SILVA, RM, SILVA, OF, FONSECA, MJO, SOARES, AG, COSTA, RA. Crescimento in vitro de fungos (Colletotrichum gloeosporioides e Cladosporium cladosporioides) isolados de frutos do mamoeiro, sob atmosfera controlada e refrigeração. Rev. Bras. Frutic.vol.28 no.3 Jaboticabal Dec, 2006. http://www.scielo.br/scielo.php?pid=S0100$29452006000300011 \&$ script $=$ sci abstract\&tlng $\equiv \mathrm{pt}$

https://g1.globo.com/pa/para/noticia/2019/04/20/1 ider-nacional-na-producao-de-cacau-para-aindanao-e-reconhecido-pelo-chocolate-queproduz.ghtml. Acesso em: 28/10/2019. 